\title{
Ação de quitosana sobre o desenvolvimento de Plasmopara viticola e Elsinoe ampelina, in vitro e em videiras cv. Isabel
}

\author{
Aline José Maia*1, Renato Vasconcelos Botelho ${ }^{1}$, Cacilda Márcia Duarte Rios Faria ${ }^{1}$, Carla Daiane Leite
}

\begin{abstract}
*Parte da dissertação de mestrado apresentada a Universidade Estadual do Centro Oeste, para a obtenção do título de mestre. Bolsista Capes; ${ }^{2}$ Departamento de Agronomia da Universidade Estadual do Centro Oeste, Rua: Simeão Camargo Vilela de Sá, 3 - Bairro Cascavel, CEP 85040080, Guarapuava, Paraná.

Autor para correspondência: Aline José Maia (alymaia2005@yahoo.com.br)

Data de chegada: 31/08/2009. Aceito para publicação em: 27/07/2010.
\end{abstract}

1672

\section{RESUMO}

Maia, A.J.; Botelho, R.V.; Faria, C.M.D.R.; Leite, C.D.. Ação de quitosana sobre o desenvolvimento de Plasmopara viticola e Elsinoe ampelina, in vitro e em videiras cv. Isabel. Summa Phytopathologica, v.36, n.3, p.203-209, 2010.

Este trabalho teve como objetivos avaliar o efeito da quitosana no controle dos fungos Plasmopara viticola e Elsinoe ampelina, agentes causais do míldio e da antracnose da videira, respectivamente. As concentrações de $0,20,40,80$ e $160 \mathrm{mg} \mathrm{L}$ ${ }^{1}$ de quitosana foram utilizadas nos seguintes experimentos: testes de crescimento micelial, de germinação de esporos e ensaio em condições de campo. Para os dois últimos ensaios, adicionou-se tratamentos padrões com mancozeb e calda bordalesa. Verificou-se redução no crescimento micelial de E. ampelina sendo que a maior concentração de quitosana $\left(160 \mathrm{mg} \mathrm{L}^{-1}\right)$ reduziu em $57 \%$ o desenvolvimento do fungo, 192 horas após incubação. Nos testes de germinação, a dose de $160 \mathrm{mg} \mathrm{L}^{-1}$ de quitosana reduziu a germinação de esporos de E. ampelina em aproximadamente $98 \%$ e de P. viticola em $60 \%$, não diferindo dos tratamentos com calda bordalesa e mancozeb. Nos ensaios a campo as maiores doses de quitosana (80 e 160 $\mathrm{mg} \mathrm{L}^{-1}$ ) apresentaram um decréscimo na severidade de antracnose entre 93 e $81 \%$. Para o míldio, a concentração de $160 \mathrm{mg} \mathrm{L}^{-1}$ apresentou um decréscimo de aproximadamente $81 \%$. Baseando-se nestes resultados, pode-se concluir que a quitosana tem um grande potencial no controle do míldio e da antracnose da videira.

Palavras-chave adicionais: Vitis labrusca, controle alternativo, míldio, antracnose, fruteiras de clima temperado.

\section{ABSTRACT}

Maia, A.J.; Botelho, R.V.; Faria, C.M.D.R.; Leite, C.D. Chitosan action on Plasmopara viticola and Elsinoe ampelina development in vitro and in grapevines cv. Isabel. Summa Phytopathologica, v.36, n.2, p.203-209, 2010.

This work aimed to evaluate the effect of chitosan on the control of fungi Elsinoe ampelina and Plasmopara viticola, the causal agents of downy mildew and anthracnose in grapevines, respectively. The concentrations of $0,20,40,80$ and $160 \mathrm{mg} \mathrm{L}$ ${ }^{1}$ chitosan were used in the following trials: mycelial growth, spore germination, and experiment in field conditions. For the last two trials standard treatments with mancozeb and bordeax mixture were added. There was a reduction in E. ampelina mycelial growth and the highest chitosan concentration $\left(160 \mathrm{mg} \mathrm{L}^{-1}\right)$ decreased by $57 \%$ the fungus development at 192 hours after incubation. In the germination tests, the concentration of $160 \mathrm{mg} \mathrm{L}^{-1}$ chitosan reduced spore germination in E. ampelina by approximately $98 \%$ and P. viticola by $60 \%$, not differing from the treatments with bordeaux mixture and mancozeb. In the field trial the highest chitosan concentrations ( 80 and $\left.160 \mathrm{mg} \mathrm{L}^{-1}\right)$ decreased anthracnose severity between 93 and $81 \%$. For downy mildew, the concentration of $160 \mathrm{mg} \mathrm{L}^{-1}$ decreased the disease by approximately $81 \%$. Based on these results, chitosan has a great potential for the control of downy mildew and anthracnose in grapevines.

Keywords: Vitis labrusca, alternative control, downy mildew, anthracnose, vines, fruit trees of temperate climates.

A videira é economicamente uma das mais importantes fruteiras cultivadas no mundo, devido às inúmeras utilizações dos seus frutos para consumo in natura e processamento (18).

As doenças fúngicas são um dos principais problemas de interesse econômico na viticultura, devido às grandes perdas registradas. Entre as principais doenças fúngicas, destacam-se o míldio, doença causada pelo fungo Plasmopara viticola, e a antracnose cujo agente causal é o fungo Elsinoe ampelina, responsáveis pelos maiores danos para a viticultura no sul do Brasil, assim como em outras regiões vitícolas do mundo. Essas doenças são especialmente sérias em anos com elevada precipitação, alta umidade relativa e longos períodos de umidade sobre folhas e frutos e, em alguns anos são tão severas a ponto de comprometer não só a produção do ano como também produções futuras (25).

O fungicida mais utilizado e mais eficiente no controle do míldio e antracnose é a calda bordalesa, entretanto, a calda bordalesa assim como todos os cúpricos, tem o inconveniente de poder causar fitotoxidez nas partes jovens da planta além de comprometer o sistema de condução, devido sua ação corrosiva. Em função destas características, os cúpricos são recomendados apenas após a frutificação. Além disso, inúmeros são os fungicidas sintéticos utilizados na viticultura em larga escala para o controle destas doenças, 
tais como: captan, metalaxyl, cymoxanil e mancozeb (1). A solubilidade destes produtos, além de sua ação sistêmica são os principais fatores de risco para a contaminação de resíduos dos subprodutos da uva (21).

De acordo com Cabras \& Angioni (7), o mosto de uva e o vinho podem apresentar resíduo de aqroquímicos. Soleas \& Goldberg (24) analisando 26 agroquímicos em sucos de uva bruto antes da fermentação, verificaram que os agroquímicos mais frequentemente encontrados foram: folpete, captan, carbaril e dimetoato. Além disso, Navarro et al. (15) observaram que quatro dias após a vinificação, o vinho apresentou teores residuais de mancozeb, penconazole, vinclozolin, fenarimol e metalaxyl. Isto, consequentemente, é o resultado do uso de fungicidas/inseticidas na viticultura, portanto, estes resíduos podem permanecer na videira e serem transferidos para o vinho (17), embora a mobilidade dos aqroquímicos de uvas para vinho é geralmente reduzido, devido ao processo de vinificação (esmagamento, prensagem, estabilização, etc) (7).

A preocupação com a segurança alimentar tem levantado questionamento sobre a agricultura moderna, aumentando a demanda pela produção orgânica, a qual preserva os agroecossistemas através do uso adequado dos recursos naturais e obtenção de alimentos de maior qualidade (23).

Diante do exposto, o uso de compostos naturais ou biodegradáveis, não-tóxicos, derivados de animais ou plantas, que apresentem efeito fungistático ou induzam a resistência natural das plantas, tem tomado destaque entre os fitopatologistas (4). Dentre estas alternativas, encontra-se a quitosana, que é um polissacarídeo obtido através da desacetilação da quitina, presente na carapaça de crustáceos (camarões, caranguejos e siris), e na parede celular de fungos (Aspergillus niger e Penicillium notatum) (26), com efeito, fungistático e indutor dos mecanismos de defesa das plantas (27). Camilli et al. (8) verificaram que a quitosana aplicada em frutos de uva cv. Itália demonstrou ser eficiente no controle de Botrytis cinerea. Muñoz et al. (14) observaram que a aplicação de 1,0 e 2,5\% de quitosana também reduziu o tamanho das lesões em frutos de tomates e bagas de uvas.

Neste sentido, o objetivo do trabalho foi de avaliar o efeito in vitro e in vivo da quitosana no controle de $P$. viticola e E. ampelina, agentes causais do míldio e antracnose da videira, respectivamente.

\section{MATERIAL E MÉTODOS}

\section{Produtos utilizados para o controle dos patógenos}

Como fonte de quitosana foi utilizado o produto comercial Fish Fértil Quitosana ${ }^{\circledR}\left(20 \mathrm{~g} \mathrm{~L}^{-1}\right.$ de quitosana, Fish Indústria e Comércio de Fertilizantes Ltda., Mogi-Mirim-SP). Como controle positivo, utilizou-se o princípio ativo mancozeb (Manzate ${ }^{\circledR} 800$, fabricado por Dow AgroSceinces Industrial LTDA-Barueri-SP), empregando-se a dose indicada no rótulo para a cultura. A calda bordalesa na proporção 1:1:100 (sulfato de cobre: cal virgem: água), produto recomendado na agricultura orgânica, foi utilizado como padrão.

\section{Teste in vitro}

Para este experimento foi realizado isolamento do patógeno, $E$. ampelina, a partir de folhas com lesões provenientes da região de Guarapuava-PR, o qual foi mantido em meio de cultura BDA (batatadextrose-ágar).

Inicialmente, adicionou-se ao meio BDA as doses de 20, 40, 80 e $160 \mathrm{mg} \mathrm{L}^{-1}$ de quitosana, além da testemunha sem adição do produto.
Em seguida, os meios foram autoclavados durante 20 minutos, a 120 ${ }^{\circ} \mathrm{C}$ e pressão de $1 \mathrm{~atm}$, e vertidos em placas de Petri de $90 \mathrm{~mm}$ de diâmetro, onde discos de $8 \mathrm{~mm}$ de diâmetro do micélio do fungo foram depositados no centro da placa.

As placas foram incubadas em câmara de crescimento (BOD) a 25 $\pm 1{ }^{\circ} \mathrm{C}$, com fotoperíodo de 16 horas de luz. Após 48, 92, 144 e 244 horas de incubação, avaliou-se o crescimento micelial através da medida do diâmetro da colônia, com auxílio de paquímetro digital. O delineamento experimental adotado foi inteiramente casualizado, com cinco tratamentos, cinco repetições e parcela experimental constituída por uma placa de Petri. Para validação dos dados o experimento foi repetido duas vezes.

Os resultados foram submetidos à análise de variância e quando significativo se estudou a regressão polinomial ao nível de 5\% probabilidade, através do programa estatístico SISVAR (12).

\section{Teste de germinação}

Para avaliar o efeito da quitosana sobre a germinação de $P$. viticola e E. ampelina utilizou-se uma alíquota de $40 \mu \mathrm{L}$ de suspensão de esporos $\left(2,2 \times 10^{6}\right.$ esporângios $\mathrm{mL}^{-1}$ e $5,8 \times 10^{6}$ conídios $\left.\mathrm{mL}^{-1}\right)$ e outra de $40 \mu \mathrm{L}$ de cada concentração de quitosana $(0,20,40,80$ e $160 \mathrm{mg} \mathrm{L}-$ $\left.{ }^{1}\right)$, além de uma única dose de calda bordalesa e mancozeb como tratamento padrão, não autoclavados. Estes foram colocadas em cada uma das cavidades de uma placa utilizada em teste ELISA (19).

As placas foram incubadas sob luz constante a $20^{\circ} \mathrm{C} \pm 1{ }^{\circ} \mathrm{C}$ e 25 $\pm 1{ }^{\circ} \mathrm{C}$ para $P$. viticola e E. ampelina, respectivamente. A porcentagem de germinação foi determinada as 2,6 e 12 horas para $P$. viticola e 12 e 24 horas para e E. ampelina, após o início do experimento, através do emprego de $20 \mu \mathrm{L}$ do corante azul algodão de lactofenol para paralisar a germinação.

A avaliação foi realizada através da observação ao microscópio ótico com aumento de 400 vezes. Contaram-se 100 esporos aleatórios por repetição, totalizando 400 esporos por tratamento. Para o fungo $P$. viticola foram considerados esporos germinados aqueles que apresentavam liberação dos zoósporos. Já para E. ampelina foram considerados como esporos germinados aqueles que apresentavam qualquer emissão do tubo germinativo. Para validação dos dados apresentados em porcentagem, o experimento foi repetido duas vezes.

Os resultados foram submetidos à análise de variância e regressão polinomial ao nível de 5\% probabilidade, através do programa estatístico SISVAR (12).

\section{Experimento em campo}

O experimento foi conduzido no período de setembro de 2008 a janeiro de 2009, em vinhedo comercial da cv. Isabel, localizado no município de Guarapuava-PR, com as seguintes coordenadas geográficas: $25^{\circ} 23^{\prime} 26^{\prime \prime} \mathrm{S}$ e $51^{\circ} 27^{\prime} 15^{\prime \prime} \mathrm{O}$, altitude de $1.120 \mathrm{~m}$. O solo foi classificado como Latossolo bruno distroférrico típico, textura muito argilosa (11). As plantas eram enxertadas sobre porta enxerto ' 1103 Paulsen', conduzidas em sistema de espaldeira, com espaçamento $2,5 \times 2,0 \mathrm{~m}$.

Os tratamentos consistiram das seguintes concentrações de quitosana: $0,20,40,80$ e $160 \mathrm{mg} \mathrm{L}^{-1}$, além do tratamento padrão com calda bordalesa, por ser um vinhedo conduzido em sistema orgânico. As pulverizações foram realizadas semanalmente com pulverizador manual até o ponto de "gotejamento", nas horas mais frescas do dia, a partir do início da brotação em 10/09/2008, perfazendo um total de 14 aplicações. $\mathrm{O}$ delineamento experimental foi em blocos ao acaso contendo cinco tratamentos e cinco repetições, sendo cada planta uma repetição. 
Com o aparecimento dos primeiros sintomas, a severidade do míldio e da antracnose da videira foi avaliada em três folhas do ápice de dois ramos por planta, previamente identificadas, utilizando-se uma escala diagramática com notas de um a doze que correspondem de $0 \%$ a $100 \%$ da área foliar lesionada (2). Com os dados da severidade foi determinada a área abaixo da curva de progresso das doenças (AACPD), segundo Campbell \& Madden (9). No total foram realizadas cinco avaliações com intervalos de sete dias.

Todos os resultados foram submetidos à análise de variância e quando significativo realizou-se a comparação de médias pelo teste de Tukey e análise de regressão polinomial ao nível de $5 \%$ probabilidade, através do programa estatístico SISVAR (12).

\section{RESULTADOS E DISCUSSÃO}

\section{Teste in vitro}

Para o teste in vitro, verificou-se redução no crescimento micelial de E. ampelina em função das concentrações de quitosana, com significância para regressão quadrática nas avaliações as 48, 96, 144 e 192 horas após incubação (Figura 1). Notou-se que na concentração de $160 \mathrm{mg} \mathrm{L}^{-1}$ houve maior efeito fungistático, reduzindo em $57 \% \mathrm{o}$ desenvolvimento de E. ampelina quando a avaliação foi realizada 192 horas após a incubação. Resultados semelhantes foram obtidos por Muñoz et al. (14) que verificaram que quitosana a $2 \%$ reduziu o crescimento micelial de Colleotrichum sp. em 63\%. Di Piero \& Garda (10) observaram redução do crescimento micelial do fungo Colletotrichum lindemuthianum, a partir de $1 \mathrm{mg} \mathrm{L}^{-1}$ de quitosana colocada em meio BDA. Liu et al. (13) verificaram total inibição do crescimento micelial de $B$. cinerea quando utilizou $5 \%$ de quitosana.

\section{Teste de germinação}

Nos ensaios realizados para a verificação da germinação, houve efeito quadrático em função das doses de quitosana para ambos os fungos. A maior dose $\left(160 \mathrm{mg} \mathrm{L}^{-1}\right)$ reduziu a germinação de esporos de E. ampelina em aproximadamente 98\%, 12 e 24 horas após incubação, não havendo diferença da quitosana em relação aos tratamentos com mancozeb e calda bordalesa (Figura 2). Para P. viticola, na maioria das avaliações, as concentrações de 80 e $160 \mathrm{mg} \mathrm{L}^{-1}$ não diferiram dos tratamentos com calda bordalesa e mancozeb (Figura 3), exceto na última avaliação em que a calda bordalesa apresentou maior redução de germinação de esporos em relação aos tratamentos com quitosana.

Propriedades fungicidas da quitosana foram relatadas para outros fitopatógenos. Ben-Shalom et al. (6) observaram que a quitosana a 50 $\mu \mathrm{g} \mathrm{L^{-1 }}$ inibiu a germinação de esporos e reduziu a elongação do tubo germinativo de $B$. cinerea, enquanto que a dose de $100 \mu \mathrm{g} \mathrm{L}^{-1}$ reduziu em $75 \%$ a germinação de uredosporos de Puccinia arachidis, agente causal da ferrugem do amendoim (22). Liu et al. (13) verificaram a total inibição da germinação de esporos quando utilizaram 0,5 e $1 \%$ de quitosana, para Penicillium expansum e B. cinerea, respectivamente.

De acordo com Benhamou (5), possivelmente este mecanismo de ação da quitosana é devido ao seu alto peso molecular e as suas cargas positivas, às quais interferem com os resíduos carregados negativamente das macromoléculas expostas sobre a superfície celular fúngica e, modificam a permeabilidade da membrana plasmática, levando à degeneração e morte do patógeno. No entanto novos testes deverão ser realizados para a confirmação da hipótese.

\section{Experimento em campo}

Para os resultados da AACPD, houve efeito quadrático em função das concentrações de quitosana para antracnose, sendo que as maiores doses de quitosana ( 80 e $160 \mathrm{mg} \mathrm{L}^{-1}$ ) apresentaram um decréscimo de aproximadamente 93 e $81 \%$, respectivamente, não diferindo do tratamento com calda bordalesa (Figura 4). Para míldio, houve efeito linear negativo em função das concentrações de quitosana, sendo que as concentrações de 40, 80 e $160 \mathrm{mg} \mathrm{L}^{-1}$ apresentaram um decréscimo de aproximadamente 52,76 e $81 \%$, respectivamente, não diferindo do tratamento com calda bordalesa (Figura 5). Aziz et al. (3) obtiveram resultados semelhantes, quando verificaram que oligômeros da quitosana na concentração de $200 \mu \mathrm{g} \mathrm{mL}^{-1}$ pulverizado isoladamente ou em combinação com sulfato de cobre $\left(\mathrm{CuSO}_{4}\right)$ a $50 \mu \mathrm{g} \mathrm{mL}^{-1}$ sobre folhas de videira $\mathrm{cv}$. Chardonnay, reduziram a severidade de $P$. viticola em

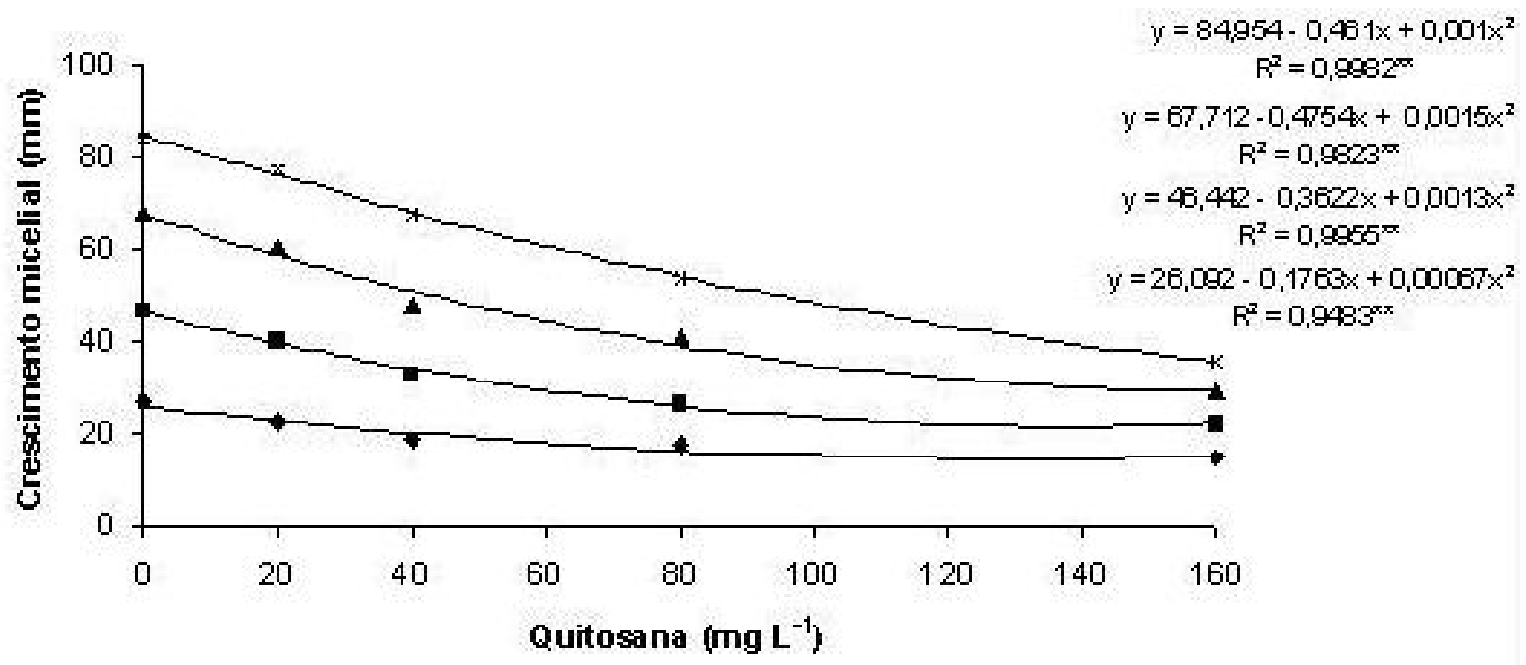

- 48 horas 96 horas 144 horas $\times 192$ horas

Figura 1. Crescimento micelial (mm) de Elsinoe ampelina em função de concentrações crescentes de quitosana, 48 , 96 , 144 e 192 horas após incubação em câmara de crescimento (Guarapuava-PR, 2008). ** Significativo a $1 \%$ de probabilidade. 

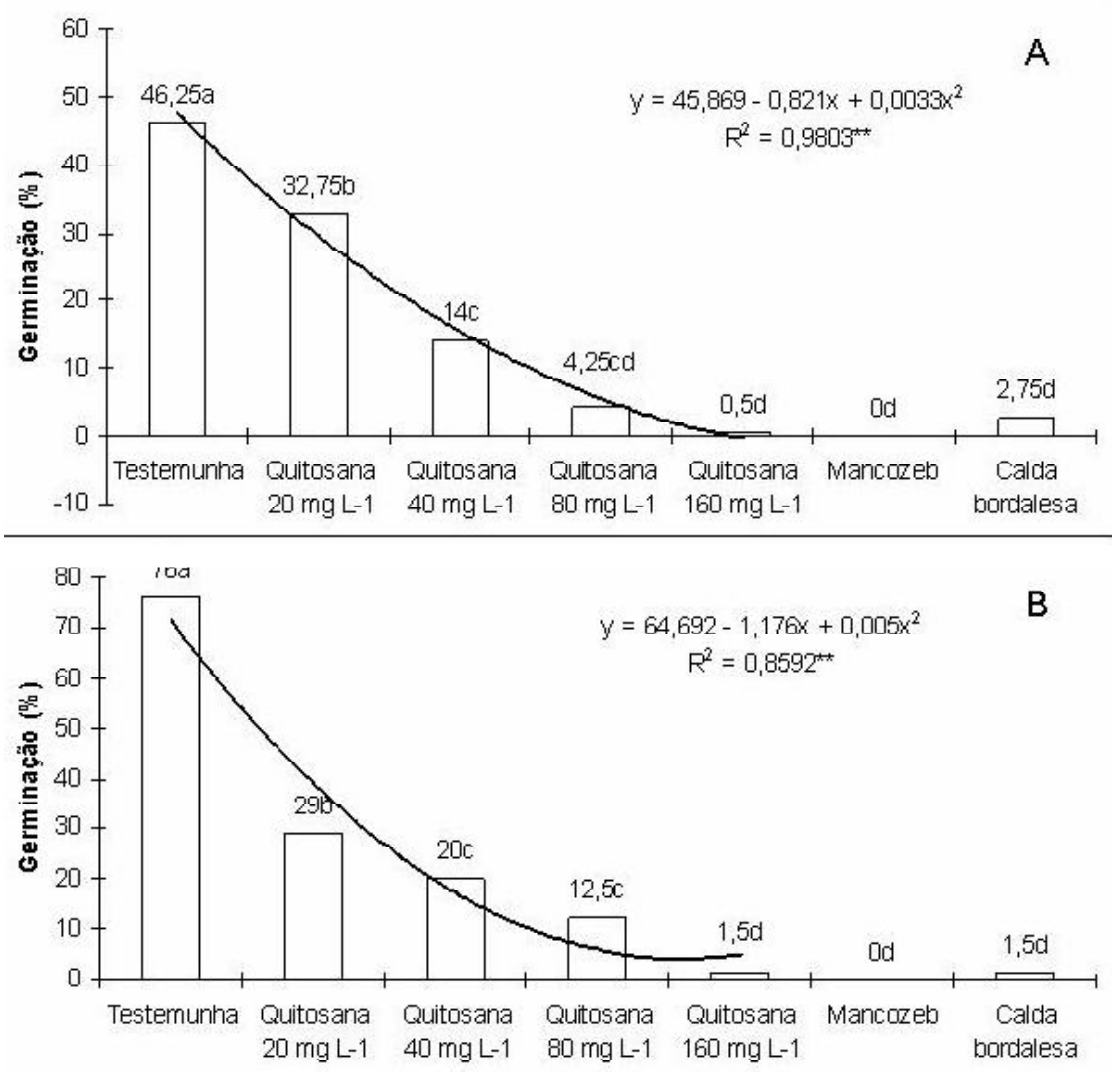

Figura 2. Germinação de esporos de Elsinoe ampelina, em diferentes concentrações de quitosana, mancozeb e calda bordalesa 12 (A) e 24 horas (B) após incubação a $25{ }^{\circ} \mathrm{C}$. ** Significativo a $1 \%$ de probabilidade.
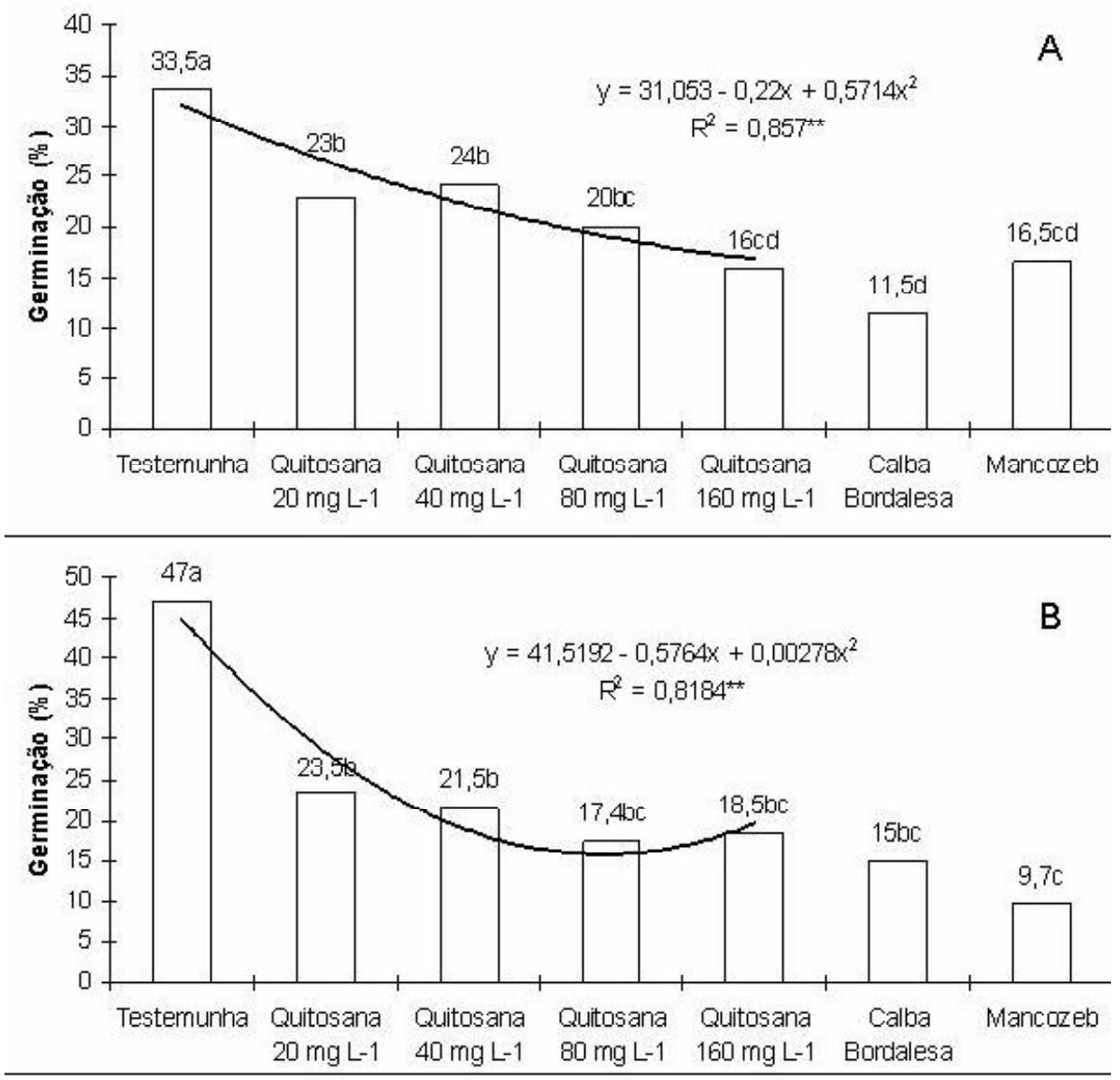

continua... 


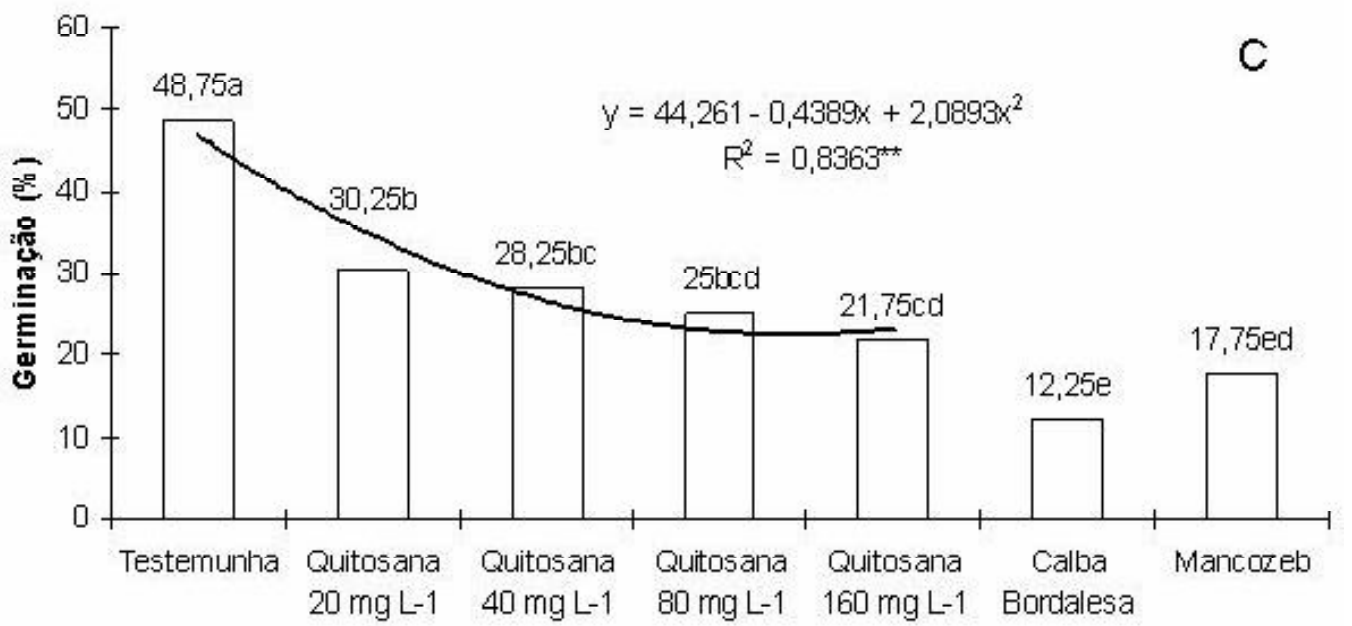

Figura 3. Germinação de esporos de Plasmopara viticola em diferentes concentrações de quitosana, calda bordalesa e mancozeb 2 (A), 6 (B) e 12 horas (C) após incubação a $20{ }^{\circ} \mathrm{C}$. **Significativo a $1 \%$ de probabilidade.

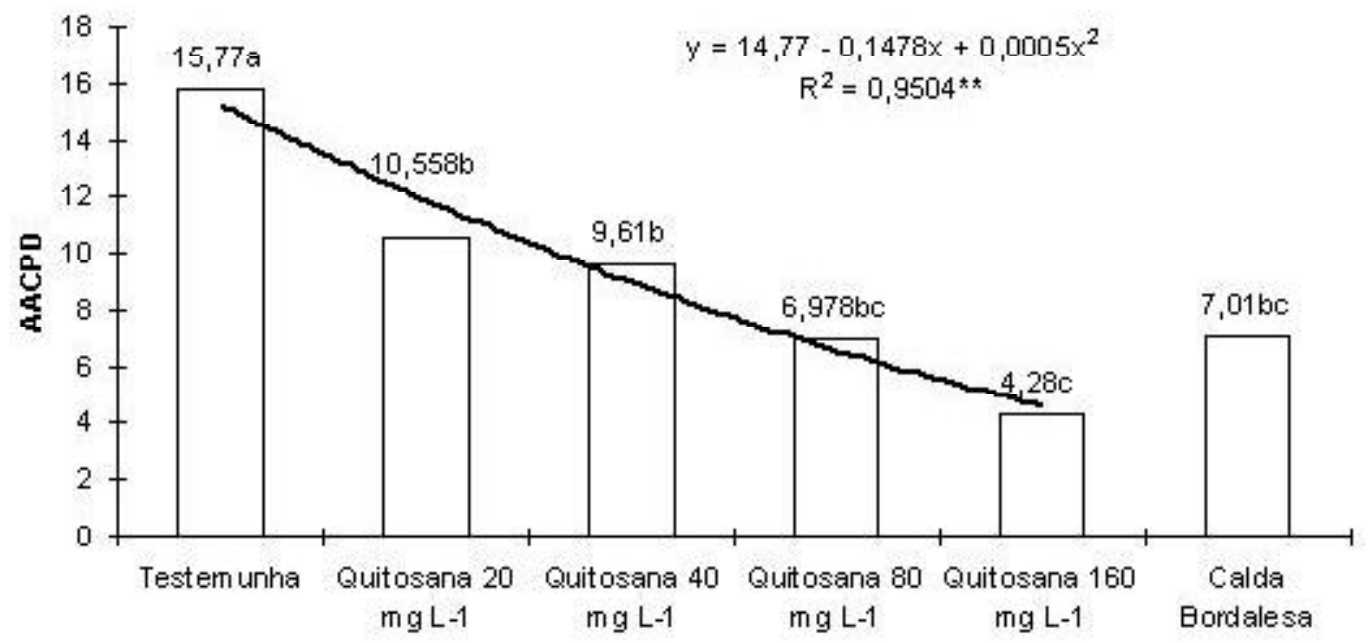

Figura 4. Efeito das doses de quitosana sobre a severidade da antracnose em plantas de videira cv. Isabel. Dados transformados em raiz quadrada de $\mathrm{Y}+$ 1.0 - SQRT $(\mathrm{Y}+1.0)$. ** Significativo a $1 \%$ de probabilidade.

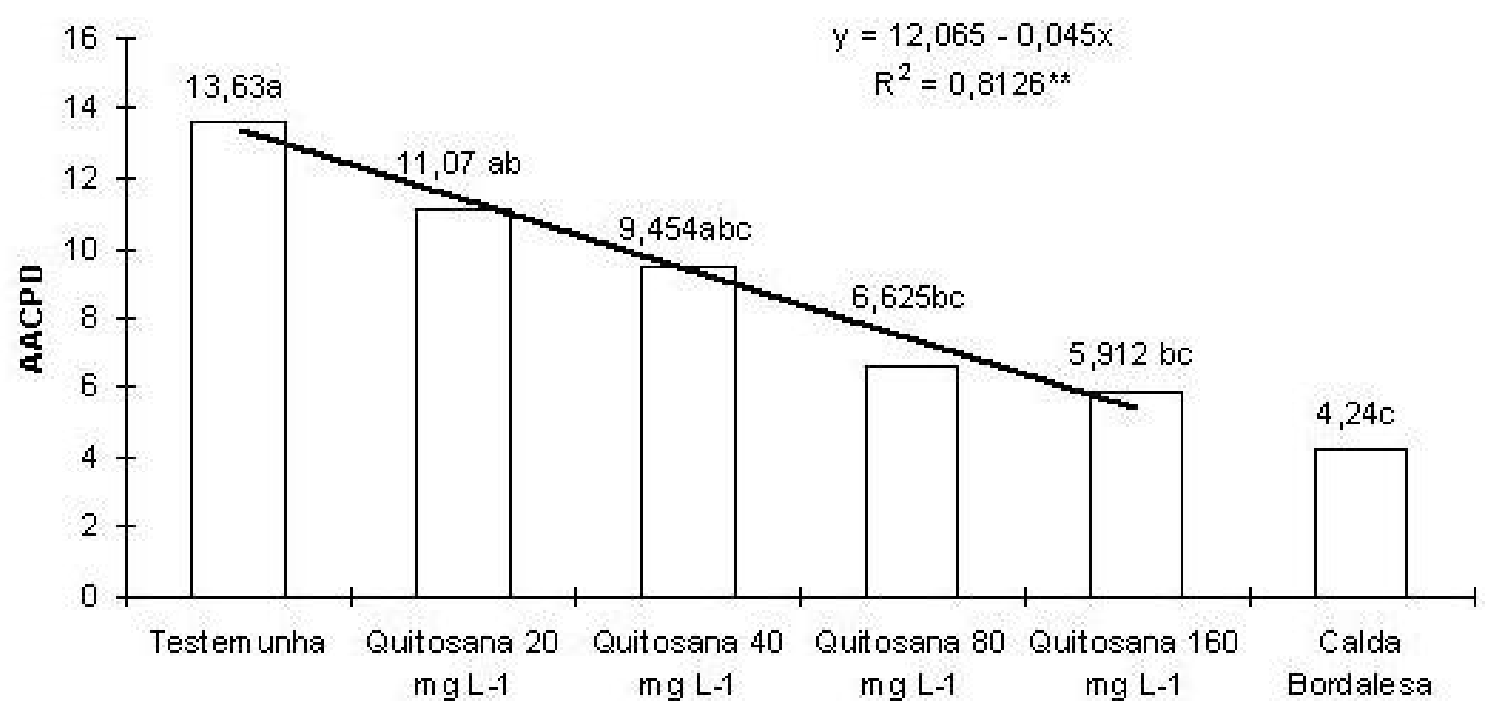

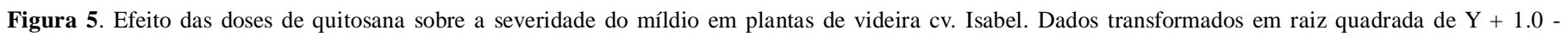
SQRT $(\mathrm{Y}+1.0)$. ** Significativo a $1 \%$ de probabilidade. 
$71 \%$ e $85 \%$, respectivamente. Do mesmo modo, Di Piero \& Garda (10), avaliando o controle da antracnose em feijoeiro-comum com o uso de diferentes doses de quitosana, verificaram redução da severidade da doença em torno de $70 \%$, quando se utilizou $9 \mathrm{mg}$ de quitosana por planta, quatro dias antes da inoculação de $C$. lindemuthianum. Estes resultados sugerem um efeito da quitosana na interação patógeno-hospedeiro, através da ação direta sobre o desenvolvimento do patógeno (16).

Além do efeito fungistático, a quitosana também tem o potencial de ativar enzimas (4) e compostos fenólicos (5) relacionadas com o mecanismo de defesa das plantas. Trabalhos realizados por Vander et al. (28) demonstraram que a quitosana pode induzir a atividade da enzima FAL (fenilalanina amônia liase) e a produção e acúmulo de fitoalexinas em milho e videira, o que também foi comprovado por Romanazzi et al. (20) em videiras. Aziz et al. (3) obtiveram a máxima indução na atividade das enzimas quitinase e $\beta$-1,3-glucanase quando utilizou $300 \mu \mathrm{g} \mathrm{mL}^{-1}$ de oligômeros de quitosana em videiras cv. Chandonnay.

Com base nos resultados obtidos, a quitosana, substância natural, biodegradável, não tóxica, pode inibir diretamente os fungos, P. viticola e E. ampelina, in vitro, como também reduzir a severidade das doenças em campo, tornando-se uma substância promissora no controle de fitopatógenos, principalmente para sistema orgânico de cultivo. Assim, este polímero pode substituir a utilização de fungicidas sintéticos, diminuindo o impacto ambiental, sem causar danos à saúde humana. Novos experimentos deverão ser conduzidos para melhor entendimento da ação da quitosana sobre os patógenos estudados.

\section{REFERÊNCIAS BIBLIOGRÁFICAS}

1. Amorim, L.; Kuniyuki, H. Doenças da Videira. In: Kimati, H.; Amorim, L.; Rezende, J.A.M.; Bergamin Filho, A.; Camargo, L.E.A. (Ed.). Manual de fitopatologia. Doenças das plantas cultivadas. 4. ed. São Paulo: Ceres, 2005. v.2, p.639-651.

2. Azevedo, L.A.S. Manual de quantificação de doenças de plantas. São Paulo: Novartis Biociências- Setor Agro, 1997. $114 \mathrm{p}$.

3. Aziz, A.; Trotel-Aziz, P.; Dhuicq, L.; Jeandet, P.; Couderchet, M.; Vernet, G. Chitosan oligomers and copper sulfate induce grapevine defense reactions and resistance to gray mold and downy mildew. Phytopathology, Saint Paul, v.96, n.11, p. 1188-1194, 2006.

4. Bautista-Baños, S.; Hernández-Lauzardo, A.N.; Valle, M.G.V.; Hernández-López, M.; Barka, E.A.; Bosquez-Molina, E.; Wilson C.L. Chitosan as a potential natural compound to control pre and postharvest diseases of horticultural commodities. Crop Protection, London, v.25, n.2, p.108-118, 2006.

5. Benhamou, N. Elicitor-induced plant defense pathways. Trends Plant Science, Chicago, v.1, n.7, p. 233-240, 1996.

6. Ben-Shalom, N.; Ardi, R.; Pinto, R.; Aki, C.; Fallik, E. Controlling gray mould caused by Botrytis cinerea in cucumber plants by means of chitosan. Crop Protection, London, v.22, n.2, p. 285-290, 2003.

7. Cabras, P.; Angioni, A. Pesticide residues in grapes, wine and their processing products. Journal of Agriculture and Food Chemistry, Washington, v.48, n.4 p.967-973, 2000.

8. Camilli, E.C.; Benato, E.A.; Pascholati, S.F.; Cia, P. Avaliação de quitosana, aplicada em pós colheita, na proteção de uva 'Itália'contra Botrytis cinerea. Summa Phytopathologica, Botucatu, v.33, n.3, p.215-221, 2007

9. Campbell, C.L.; Madden, L.V. Introduction to Plant Disease Epidemiology. New York: John. Wiley, 1990. 532p.
10. Di Piero, M.D.; Garda, M.V. Quitosana reduz a severidade da antracnose e aumenta a atividade de glucanases em feijoeirocomum. Pesquisa Agropecuária Brasileira. Brasília, v. 43, n.9, p.1121-1128, 2008.

11. EMPRESA BRASILEIRA DE PESQUISA AGROPECUÁRIA. Centro Nacional de Pesquisa de Solos. Sistema brasileiro de classificação de solos, 2.ed. Rio de Janeiro: EMBRAPA, 2006. 306 p.

12. Ferreira, D.F. Análises estatísticas por meio do SISVAR (Sistema para análise de variância) para Windows versão 4.0. In: Reunião anual da região brasileira da sociedade internacional de biometria, 45., 2000, São Carlos. Anais... São Carlos: UFSCar, p.255-258, 2000.

13. Liu, J.; Tian, S.; Meng, X.; Xu, Y. Effects of chitosan on control of postharvest disease and physiological response of tomato fruit. Postharvest Biology and Tecnology, Amsterdam, v. 44, n.3, p.300-306, 2007.

14. Muñoz, Z.; Moret, A.; Garcés, S. Assessment of chitosan for inhibition of Colletotrichum sp. on tomatoes and grapes. Crop Protection, London, v. 28, n.1, p. 36-40, 2009.

15. Navaro, S.; Barba, A.; Oliva, J.; Navaro, G.; Pardo, F. Evolution of residual levels of six pesticides levels during elaboration of red wines. Effect of wine-making procedures in their disappearance. Journal of Agriculture and Food Chemistry, Washington, v.47, p.264-270, 1999.

16. Oh, S.K.; Cho, D.; Yu, S.H. Development of integrated pest management techniques using biomass for organic farming (I). Suppression of late blight and Fusarium wilt of tomato by chitosan involving both antifungal and plant activating activities. Korean Society of Plant Pathology, Suwon, v.14, p.278-285, 1998.

17. Oliva, J.; Payá, P.; Cámara, M.A.; Barba, A. Removal of famoxadone, fluquinconazole and trifloxystrobin residues in red wines: Effects of clarification and filtration processes. Journal of Environmental Science and Health, Part B: Pesticides, Food Contaminants and Agricultural Wastes, London, v.42, n.7, p.775, 2007.

18. Pommer, C.V.; Maia, M.L. Introdução. In: Pommer, C.V. (Ed.). Uva: tecnologia da produção, pós-colheita e mercado. Porto Alegre: Cinco Continentes, 2003. p.11-36.

19. Regente, M.C.; Oliva, C.R.; Ffeldman, M.L.; Castagnaro, A.P.; Canal, L.A. sunflower leaf antifungal peptide active against Sclerotinia sclerotiorum. Physiologia Plantarum, Sweden, v. 100 , p.178-182, 1997

20. Romanazzi, G.; Gabler, F.M.; Smilanick, J.L. Preharvest chitosan and postharvest UV irradiation treatments suppress gray mold of table grapes. Plant Disease, Saint Paul, v. 90, n.4, p.445-450, 2006.

21. Rose, G.; Lane, S.; Jordan, R. The fate of fungicide and insecticide residues in Australian wine grape by-products following field application. Food Chemistry, Oxford, v.117, n. 4, p.634-640, 2009 .

22. Sathiyabama M.; Balasubramaniam R. Chitosan induces resistance components in Arachis hipogaea against leaf rust caused by Puccinia arachidis Speg. Crop Protection, London, v.17, n.4, p307-313, 1998.

23. Schiûerstein, H.N.J.; Oude Ophuis, P.A.M. Health-related determinants of organic food consumption in the Netherlands. Food Quality and Preference, France, v.9, n. 3, p.119$133,1998$.

24. Soleas, G.J.; Goldberg, D.M. Pesticides residues in unfermented grape juices and raw wines: a 5 -year survey of more than 3000 products. Journal of Wine Research, London, v.11, n. 3, p.197-207, 2000.

25. Sônego, O.R.; Garrido, L.R. Doenças Fúngicas. In: Fajardo, T.V.M. (Ed.). Uvas para processamento fitossanidade. Brasília: EMBRAPA informação tecnológica, 2003. $131 \mathrm{p}$.

26. Tan, S.C.; Tan, T.K.; Wong, S.M.; Khor, E. The chitosan yield of Zygomycetes at their optimum harvesting time. Carbohydrate Polymers, London, v.30, n.4, p.239-242, 1996. 
27. Terry, L.A.; Joyce, D.C. Elicitors of induced disease resistance in postharvest horticultural crops: a brief review. Postharvest Biology and Technology, Amsterdam, v.32, n.1, p.113,2004 .
28. Vander, P.; Varum, K.M.; Domard, A.; El-Gueddari, N.E.; Moerschbacher, B.M. Comparison of the ability partially N-acetylated chitosans and chitooligosaccharides to elicit resistance reactions in wheat leaves. Plant Physiology, Urbana, v. 118, p. $1353-1359,1998$. 